\title{
Mild Conditions for the Removal of Acid-Labile Protective Groups
}

\section{Citation}

Myers, Andrew G., Marry Ann M. Fundy, and Peter A. Lindstrom, Jr. 1988. Mild conditions for the removal of acid-labile protective groups. Tetrahedron Letters 29(44): 5609-5612.

\section{Published Version}

http://dx.doi.org/10.1016/S0040-4039(00)80825-4

\section{Permanent link}

http://nrs.harvard.edu/urn-3:HUL.InstRepos:2958572

\section{Terms of Use}

This article was downloaded from Harvard University's DASH repository, and is made available under the terms and conditions applicable to Other Posted Material, as set forth at http:// nrs.harvard.edu/urn-3:HUL.InstRepos:dash.current.terms-of-use\#LAA

\section{Share Your Story}

The Harvard community has made this article openly available.

Please share how this access benefits you. Submit a story.

\section{Accessibility}




\section{MILD CONDITIONS FOR THE REMOVAL OF ACID-LABILE PROTECTIVE GROUPS ${ }^{\dagger}$}

Andrew G. Myers,* Mary Ann M. Fundy and Peter A. Lindstrom, Jr.

Contribution No. 7819 from the Arnold and Mabel Beckman Laboratories of Chemical Synthesis

California Institute of Technology, Pasadena, California 91125

Summary: Hydrogen peroxide-trichloroacetic acid is an effective reagent combination for the mild cleavage of acid-labile protective groups.

In the course of research directed towards a synthesis of neocarzinostatin chromophore and related compounds, we required a means to transform the dimethyl acetal 1 into the aldehyde $2 .{ }^{1}$ An extensive survey of aqueous acid-cosolvent combinations failed to reveal conditions which would effect hydrolysis of the dimethyl acetal group of 1 without competitive opening of the epoxide ring. The ability of hydrogen peroxide to enter into acetal exchange reactions has long been recognized, though reported reaction conditions (acetal and hydrogen peroxide, neat, $\left.70^{\circ} \mathrm{C}, 15 \mathrm{~h}\right)^{2}$ have perhaps dissuaded wider exploration of the method. We find that 1 is cleanly transformed into the mixed hydroperoxy methyl acetal (stereochemistry not determined) upon treatment with $70 \%$ hydrogen peroxide (caution--see below)-trichloroacetic acid in 1:1 $t$-butyl alcohol-dichloromethane at $0-23^{\circ} \mathrm{C}$. This hydroperoxide was stable to isolation and could be purified by flash column chromatography, but for convenience and safety was typically directly reduced by treatment with methanolic dimethyl sulfide solution, ${ }^{3}$ providing the aldehyde 2 in $80 \%$ (overall) yield after chromatographic purification. The presence of water in the
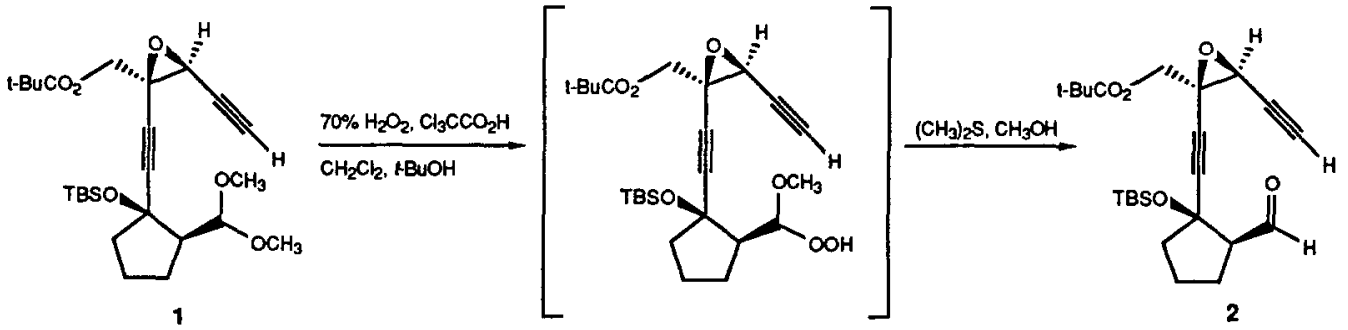

† Dedicated to the memory of our friend and colleague, Peter A. Lindstrom, Jr. 
reaction mixture is markedly deleterious; use of $90 \%$ hydrogen peroxide leads to faster reaction with a slight increase in yield whereas reaction with $30 \%$ hydrogen peroxide is prohibitively slow and epoxidering-opening is observed. The substantial hazard in working with the former reagent and its removal from the commercial market have led us to develop our procedure around the commercially available (FMC), and safer, $70 \%$ solution. A particular advantage of this sequence are the mild conditions of final deprotection; ${ }^{3}$ neither aldehyde epimerization nor elimination of the $\beta$-silyloxy group are observed. By contrast, subjection of the acetal 3 to acidic hydrolysis conditions ( $1 \mathrm{M} p$-toluenesulfonic acid, $3: 1$ THF: $\mathrm{H}_{2} \mathrm{O}, 23^{\circ} \mathrm{C}, 3$ days) produces competitively the $\alpha, \beta$-unsaturated aldehyde 4 . It should be noted that this alternative preparation of hydroperoxy alkyl acetals provides access to a number of useful oxidative transformations as well. 4

We have also found that the tetrahydropyranyl group of $5(9 \mathrm{~h}, 80 \%)^{1}$ and the trityl group of 6 (24 h, $85 \%)^{5}$ are smoothly removed under similar reaction conditions, suggesting potential for wider application of the method in the removal of acid-labile protective groups and indicating that complications arising from free-radical or peracid impurities are, at best, minor.

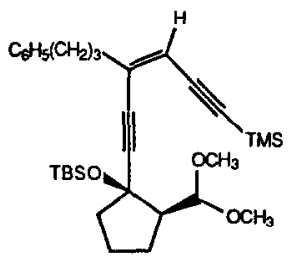

3

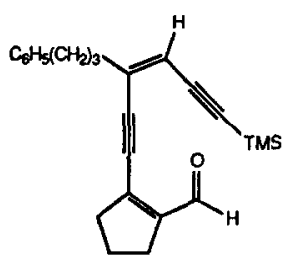

4

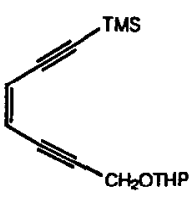

5

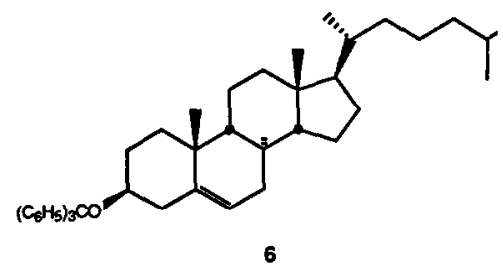

Extreme caution should be exercised in handling mixtures of organic materials and high-strength hydrogen peroxide. ${ }^{6}$ Explosions have resulted upon distillation of hydrogen-peroxide-treated tetrahydropyranyl ethers. ${ }^{7}$ For this reason we have made it a practice not to concentrate organic solutions which have been in contact with hydrogen peroxide without first treating with dimethyl sulfide-methanol and then only after obtaining a negative indication with EM Quant ${ }^{\circledR}$ Peroxide Test Paper. ${ }^{7}$ All manipulations with high-strength hydrogen peroxide solution should be carried out behind a good safety shield. Employing these and other safety precautions, described in greater detail in the experimental procedure which follows, we have never experienced a mishap in the laboratory. 
The superior nucleophilicity of hydrogen peroxide (relative to water) ${ }^{8}$ is evident in the smooth transacetalization of 1 under conditions too weakly acidic for reaction with water. A more subtle distinction is the difference in relative rates of attack exhibited by these two nucleophiles towards the epoxide and acetal groups of $1 .^{9}$ With care in execution, we feel that the procedure described herein provides a useful addition to existing methods for the removal of acid-labile protective groups. ${ }^{10}$

\section{Experimental}

All manipulations with hydrogen peroxide and peroxide-treated solutions are carried out behind a sturdy blast shield.

A $50-\mathrm{mL}$ round-bottom flask was charged with dimethyl acetal 1 ( $327 \mathrm{mg}, 0.683 \mathrm{mmol}$ ), anhydrous $t$-butyl alcohol-dichloromethane solution $(1: 1,15 \mathrm{~mL})$ and a teflon-coated magnetic stir bar which had been carefully cleaned to remove adhering metal contaminants. The mixture was cooled in an ice bath and $70 \%$ hydrogen peroxide solution (FMC, $2.80 \mathrm{~mL}$ ) was administered slowly from a 5-mL glass syringe fitted with a polyethylene needle (gloves should be worn as hydrogen peroxide causes severe chemical burns). A solution of trichloroacetic acid in anhydrous dichloromethane ( $3 \mathrm{M}, 0.36 \mathrm{~mL}$, 1.6 equiv) was added and the ice bath was removed. After stirring at $23{ }^{\circ} \mathrm{C}$ for $35 \mathrm{~h}$, the clear, homogeneous solution was carefully poured into ice-cold brine $(100 \mathrm{~mL})$. The organic layer was brought to $60 \mathrm{~mL}$ volume by the addition of 1:1 ethyl acetate:hexanes and the layers were separated (this and all subsequent aqueous layers were treated with $2 \mathrm{M}$ aqueous sodium thiosulfate solution prior to disposal). The organic layer was washed again with ice-cold brine $(100 \mathrm{~mL})$, then slowly added to an ice-cold mixture of $1 \mathrm{M}$ aqueous sodium bicarbonate solution and $2 \mathrm{M}$ aqueous sodium thiosulfate solution (1:1, $100 \mathrm{~mL}$ ). After separation, the organic layer was washed with saturated aqueous sodium bicarbonate solution $(50 \mathrm{~mL})$ and then treated with methanolic dimethyl sulfide solution (5:1 methanol:dimethyl sulfide, $24 \mathrm{~mL}$ ). The progress of hydroperoxide reduction was conveniently monitored by thin-layer chromatography $\left(\mathrm{R}_{f}\right.$ values $0.45,0.35$ and 0.48 , respectively, for 1 , the hydroperoxy methyl acetal and 2, 20\% ethyl acetate-hexanes) and was judged complete after $45 \mathrm{~min}$. Peroxide analysis at this point with EM Quant ${ }^{8}$ Peroxide Test Paper was negative. The solution was concentrated and the product purified by flash column chromatography ( $87: 10: 3$ hexanes:ethyl acetate:triethylamine) to provide the aldehyde 2 as a colorless oil ( $236 \mathrm{mg}, 80 \%)$. 


\section{Acknowledgement}

Generous financial assistance from the National Institutes of Health (CA-47148-01) and Merck \& Co., Inc., a Dreyfus New Faculty Award (to AGM) and a Summer Undergraduate Research Fellowship (to PAL) are gratefully acknowledged.

\section{References}

(1) Our synthetic materials, here designated as 1 and 2, are composed of a 1:1 mixture of diastereomers, cis about the cyclopentane ring with $S, S$ epoxide stereochemistry. Preparation of compounds 1,3 and 5 will be described elsewhere.

(2) Rieche, A.; Bischoff, C. Chem. Ber. 1961, 94, 2722.

(3) Pappas, J.J.; Keaveney, W.P.; Gancher, E.; Berger, M. Tetrahedron Lett. 1966, 4273.

(4) Schreiber, S.L.; Liew, W-F. Tetrahedron Lett. 1983, 2363.

(5) Blickenstaff, R.T. J. Am. Chem. Soc. 1960, 82, 3673.

(6) Shanley, E.S.; Perrin, J.R. Jet Propul. 1958, 28, 382; available within FMC Technical Bulletin 46.

(7) Meyers, A.I.; Schwartzman, S.; Olson, G.L.; Cheung, H-C. Tetrahedron Lett. 1976, 2417.

(8) Hiatt, R. In Organic Peroxides; Swern, D. Ed.; Wiley: New York, 1971; Vol. 2, Chapter I.

(9) For interesting examples of relative rate differences in base-catalyzed reactions of hydrogen peroxide and water, see: Evans, D.A.; Britton, T.C.; and Ellman, J.A. Tetrahedron Lett. 1987, 28, 6141.

(10)The $\alpha$-effect nucleophile semicarbazide has recently been used for acetonide removal in an advanced intermediate in the total synthesis of Forskolin: Corey, E.J.; Jardine, P.D.S.; Rohloff, J.C. J. Am. Chem. Soc. 1988, 110, 3672.

(Received in USA 16 August 1988) 